\title{
OFFLINE AND ONLINE SIGNATURE VERIFICATION SYSTEMS:
}

\section{A SURVEY}

\author{
Yogesh V.G. ${ }^{1}$, Abhijit Patil ${ }^{2}$ \\ ${ }^{I}$ Assistant Professor, Department of MCA, BKIT Bhalki, Karnataka, India \\ ${ }^{2}$ Assistant Professor, Department of Computer Science, KASC Bidar, Karnataka, India
}

\begin{abstract}
In recent years, due to the extraordinary diffusion of the internet in our daily life and simultaneously growing need of personal verification in many daily applications has driven signature verification system as an important aspect. This paper presents the survey about the offline \& online signature verification system. Feature extraction stage is the most important stage in both online \& off-line signature verification. The successful implementation of any such verification system depends mainly on how effectively the features have been extracted \& used for classification. The robust features yield a successful verification system. Hence, in this paper, we are focusing on to put up with various feature extraction techniques \& classifiers employed by various authors to attempt signature verification system. This paper summarizes different techniques used in signature verification system with their merits and demerits.
\end{abstract}

Keywords: offline, online, signature verification.

$* * *$

\section{INTRODUCTION}

In the past few decades the technology is rapidly growing at a very fast pace. Due to the advent of computers \& internet lot of transactions are going online as well as offline. The increase in number of transactions is the boon of this latest cutting edge technology that can be done at a mind boggling speed.

The technology has increased the convenience but at the same time security is at the stake, lot of false transactions are going around because of forgeries done by some anti-social elements which is leading to huge financial loss to the concerned person \& to the society as a whole. We need some mechanism by which we can verify that the concerned transaction is genuine \& not the forged one.

One useful methodology is the biometric system. It is used to confirm \& verify the identity of the concerned user. Biometric are of two types 1) Physical 2) behavioral. In physical biometric individual person's iris, palm, thumb impression can be used to recognize \& verify the individual. Whereas the behavioral biometric could be signature, voice etc. However, if a single biometric of an individual is under study, then it is referred as unimodal biometrics. if more than one biometrics of an individual is used for verification is called as multimodal biometric. In unimodal biometric systems there exists number of problems such as noisy data, spoof attacks, restricted degrees of freedom, intra-class variations, non-universality, and unacceptable error rates. Multimodal biometric system that integrates the evidence presented by multiple sources of information of an individual and it is an alternative to overcome some of the limitations of the unimodal. There are number of algorithms have been presented on multimodal and uinimodal biometrics to deal the authenticity of an individual. However, in this paper, we consolidated the gist of unimodal algorithms and their performance in signature verification system. Signature is an ultimate biometrics to authenticate an individual. The signatures are used in cheques, legal transactions etc to determine the individual identity. The legalization of any document takes place by putting a signature on it. This problem can be dealt in two ways:

1) Online signature verification

2) Offline signature verification

In some transactions online signatures are used where the user is provided with a pen based tablet. The user has to do his signature on that tablet then that signature will be recorded in the system/computer. Signature trajectory, pen pressure, pen downs \& pen ups will be captured by the tablet $\&$ sent to the system/computer. Then it will verify with the database whether it is genuine or forged one.

On the other hand offline signature is the one which can be obtained by signing on the simple paper $\&$ then scanning it to the computer. Now the system will judge whether it is a genuine or forged one. Offline signature does not require any specific hardware whereas online signatures require a lot of hardware \& software to determine genuineness.

As a rule it is impossible to know in advance which of the approaches is novel. In this paper, we have done a survey on the various methods used in offline \& online signature verification with its accuracies.

\subsection{Signature Characteristics}

A signature is handwritten graphical representation which is used to authenticate individuality. Signature of a person may vary according to his mood, health etc. Even the genuine signer may not replicate his own signature as it is, some 
minor change will be there. Hence, it is difficult to distinguish that whether signature is genuine or forged one.

A person's signature often changes depending on some elements such as mood, fatigue, time etc. Great inconsistency can even be observed in signatures according to their country, habits, psychological or mental state, physical and practical conditions.

Signatures can be treated as an image because a person may use any symbol, line, Curve \& letter or group of letters as a signature Shown in fig1. Hence it is a perfect candidate for image processing \& pattern recognition.

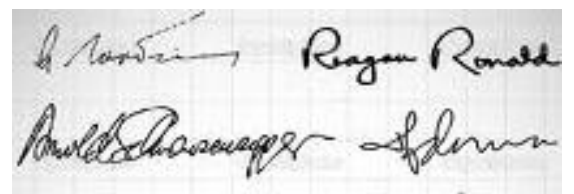

Fig.1. A sample of signatures

\section{METHODOLOGIES}

The methodology employed for offline and online signature verification is depicted in Figure 2. The methodology involves signature acquisition, pre-processing, feature extraction and comparison with an enrolled signature template as a knowledge base to draw the decision between genuine and forged one. Each steps of the methodology is explained in the following Subsections.

\subsection{Image Acquisition}

Signature image acquisition is a crucial stage of any recognition system. The resolution, skew and isolated components of signature makes the problem more complex.

\subsection{Pre-Processing (Noise Removal)}

This involves Normalizing, Converting a grey scale image to a binary image or its vice-versa, removing of spurious pixels (noise) etc.

\subsection{Feature Extraction}

Features can be classified in to two types global \& local. Global features describe the signature as a whole for ex: width \& height of signature, width to height ratio. Local features are confined to a limited portion of the image/signature for ex: a grid of the signature.

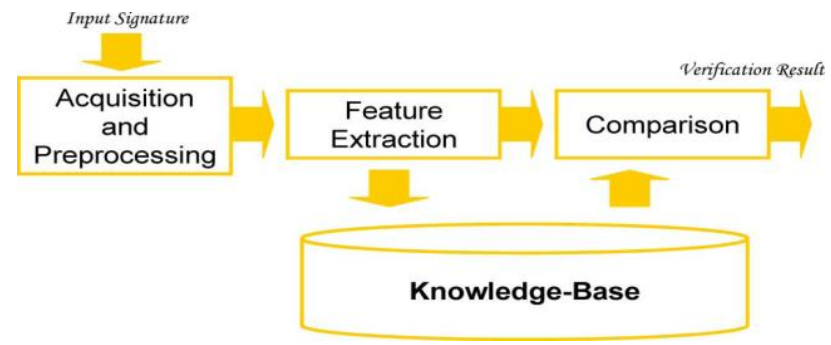

Fig 2: signature verification system
Table -1: Different approaches used in offline signature verification

\begin{tabular}{|c|c|c|c|}
\hline Features & Classifiers & Dataset & $\begin{array}{l}\text { Accurac } \\
\mathbf{y}\end{array}$ \\
\hline $\begin{array}{l}\text { Random } \\
\text { Transform \& } \\
\text { Fractal } \\
\text { Dimension [1] }\end{array}$ & SVM & $\begin{array}{l}\text { SVC- } \\
2004\end{array}$ & - \\
\hline $\begin{array}{l}\text { Curve let } \\
\text { Transform, edge } \\
\text { detection, } \\
\text { Hough } \\
\text { Transform, [2] }\end{array}$ & $\begin{array}{l}\text { Modular Neural } \\
\text { Network(MNN)wi } \\
\text { th } \\
\text { Mandeni Fuzzy } \\
\text { Inference System, } \\
\text { Artificial Neural } \\
\text { Network }\end{array}$ & $\begin{array}{l}\text { Used } \\
270 \\
\text { Images } \\
210- \\
\text { Trannin } \\
\text { g } \\
60- \\
\text { Testing }\end{array}$ & $96 \%$ \\
\hline $\begin{array}{l}\text { Projection } \\
\text { \&Local point } \\
\text { ensity,COG, } \\
\text { Spatial } \\
\text { Frequency } \\
\text { Distribution [4] }\end{array}$ & $\begin{array}{l}\text { Euclidean } \\
\text { Distance, Least } \\
\text { Square Error }\end{array}$ & $\begin{array}{l}100 \\
\text { Image }\end{array}$ & - \\
\hline $\begin{array}{l}\text { Statistical } \\
\text { Analysis } \\
\text { Using Chi- } \\
\text { Square Test [6] }\end{array}$ & $\begin{array}{ll}\text { PSO } & -\mathrm{NN} \\
\text { Algorithm } & \\
\text { Probability } & \end{array}$ & GPDS & $78 \%$ \\
\hline $\begin{array}{l}\text { Projection } \\
\text { \&Local point } \\
\text { Density, } \\
\text { COG, } \\
\text { Spatial } \\
\text { Frequency } \\
\text { Distribution [3] }\end{array}$ & $\begin{array}{l}\text { Feature Vector, } \\
\text { Correlation, } \\
\text { Mean \& deviation }\end{array}$ & - & - \\
\hline $\begin{array}{l}\text { Radon } \\
\text { Transformation } \\
\text { Fractal } \\
\text { Dimension With } \\
\text { Kart method[5] }\end{array}$ & $\begin{array}{l}\text { SVM Based on } \\
\text { (SRM) } \\
\text { SVM } 3 \text { kernels }\end{array}$ & $\begin{array}{l}\text { SVC } \\
2004\end{array}$ & $\begin{array}{l}92.2 \% \text { of } \\
\text { FAR } \\
10 \% \text { of } \\
\text { FRR }\end{array}$ \\
\hline $\begin{array}{l}\text { Interpolation } \\
\text { Using NN }\end{array}$ & $\begin{array}{l}\text { KNN, } \\
\text { Learning Vector } \\
\text { Quantization, } \\
\text { Euclidean } \\
\text { Distance Metric }\end{array}$ & $\begin{array}{l}945 \\
\text { Signs }\end{array}$ & $94 \%$ \\
\hline $\begin{array}{l}\text { Energy method } \\
\text {,Directional } \\
\text { Feature Method } \\
\text {,Chain Code } \\
\text { used as a } \\
\text { Directional } \\
\text { Feature [ 8 ] }\end{array}$ & Neural Network & $\begin{array}{l}100 \\
\text { signs } \\
50 \text { forge } \\
\text { d } \\
50 \\
\text { genuine }\end{array}$ & \\
\hline $\begin{array}{l}\text { Global \& Local } \\
\text { features , } \\
\text { Distance } \\
\text { Matrices } \\
\text {,Geometric } \\
\text { Normalization } \\
\text { [9] }\end{array}$ & $\begin{array}{l}\text { Euclidean } \\
\text { Distance, } \\
\text { Gaussian } \\
\text { Empirical Rule, } \\
\text { CMC curve }\end{array}$ & $\begin{array}{l}5400 \\
\text { Signs }\end{array}$ & $97.17 \%$ \\
\hline
\end{tabular}




\begin{tabular}{|c|c|c|c|}
\hline $\begin{array}{l}\text { Static Image } \\
\text { Processing, } \\
\text { Novel Feature } \\
\text { Extraction [ 10 ] }\end{array}$ & $\begin{array}{l}\text { Euclidean } \\
\text { Distance }\end{array}$ & $\begin{array}{l}\text { 160Sign } \\
\text { s } \\
80 \\
\text { genuine } \\
80 \\
\text { Skilled } \\
\text { forged }\end{array}$ & $\begin{array}{l}\text { FAR is } \\
1 \% \\
\text { FRR is } \\
0.5 \%\end{array}$ \\
\hline $\begin{array}{l}\text { Grid Features, } \\
\text { Global Features } \\
{[11]}\end{array}$ & $\begin{array}{l}\text { KNN Classifier, } \\
\text { Neural } \\
\text { Network(NN) }\end{array}$ & $\begin{array}{l}600 \\
\text { sign }\end{array}$ & $\begin{array}{l}\text { FAR is } \\
4.16 \\
\text { FRR is } \\
7.51 \%\end{array}$ \\
\hline $\begin{array}{l}\text { Binary Feature } \\
\text { Vector } \\
\text { Gradient } \\
\text { Direction } \\
\text { Extraction, } \\
\text { Aquinas Spatial } \\
\text { Pyramid [14] }\end{array}$ & $\begin{array}{l}\text { Automatic } \\
\text { Classifier \& } \\
\text { Manual Classifier }\end{array}$ & $\begin{array}{l}\text { CEDA } \\
\text { R \& } \\
\text { GPDS }\end{array}$ & $\begin{array}{l}92 \% \text { on } \\
\text { CEDAR } \\
87 \% \text { on } \\
\text { GPDS }\end{array}$ \\
\hline $\begin{array}{l}\text { Discrete Wavelet } \\
\text { Transformation, } \\
\text { Image } \\
\text { Registration , } \\
\text { Image Fusion } \\
{[12]}\end{array}$ & $\begin{array}{ll}\text { Registration by } \\
\text { finding COG \& } \\
\text { with } \\
\text { Euclidean } \\
\text { Distance }\end{array}$ & 90 sign & $92.2 \%$ \\
\hline $\begin{array}{l}\text { Graph } \\
\text { Matching(Biparti } \\
\text { te Graph), } \\
\text { Radon } \\
\text { Transformation } \\
\text { [13] }\end{array}$ & $\begin{array}{l}\text { Euclidean } \\
\text { Distance, } \\
\text { Cross Validation, } \\
\text { HMM, } \\
\text { Hungarian } \\
\text { Method }\end{array}$ & & - \\
\hline
\end{tabular}

Vigorous research has been pursued in signature verification System for a number of years. In the area of Signature verification, especially offline Signature verification, different technologies have been used and still the area is to be explored. The techniques used by different researchers differ in the type of features extracted, the training and testing methods used, and classification, verification model used.

\subsection{Comparison/Classification:}

This is based on an algorithm which is capable of deciding whether to accept or reject the Signature which is under test. False Acceptance Rate :the probability that the system incorrectly matches the input pattern to a non-matching template in the database. It measures the percent of invalid inputs which are incorrectly accepted. In case of similarity scale, if the person is an imposter in reality, but the matching score is higher than the threshold, then he is treated as genuine.

False Rejection Rate: the probability that the system fails to detect a match between the input pattern and a matching template in the database. It measures the percentage of valid inputs which are incorrectly rejected.

Table 1 depicts the different approaches used in offline sign verification along with its accuracy.
Table 2 depicts the different approaches used in online sign verification along with its accuracy

Table -2: Different approaches used in online signature verification

\begin{tabular}{|c|c|c|}
\hline Features \& Classifiers & $\begin{array}{l}\text { Dataset } \\
\text { Users/Sig }\end{array}$ & Accuracy \\
\hline $\begin{array}{l}\text { BPNN, } \\
\text { Probabilistic model \& } \\
\text { Fusion [15] }\end{array}$ & SVC 2004 & $\begin{array}{l}\mathrm{FRR}=0.3 \\
\mathrm{FAR}=0.5\end{array}$ \\
\hline $\begin{array}{l}\text { Dynamic time warping } \\
\text { [16] }\end{array}$ & SVC 2004 & $\begin{array}{l}\mathrm{FRR}=5.5 \\
\mathrm{FAR}=4.13\end{array}$ \\
\hline $\begin{array}{lr}\text { Support } & \text { Vector } \\
\text { Machines } & \text { Based on } \\
\text { LCSS } & \text { Kernel } \\
\text { Function[17] } & \\
\end{array}$ & SVC 2004 & ERR 6.84 \\
\hline $\begin{array}{lrl}\text { Neural } & \text { Networks } \\
\text { llassifiers \& \& } & \text { Fuzzy } \\
\text { Inference[24] } & \end{array}$ & $20 / 600$ & $\begin{array}{l}F R R=21.5 \\
F A R=3.5 \\
F R R=3.5 \\
F A R=0.0\end{array}$ \\
\hline HMM/ANN[18] & MCYT & ERR 0.12 \\
\hline PWC ,HMM [ 20] & MCYT & $\begin{array}{l}\text { EER } 6.67 \\
\text { EER } 2.12\end{array}$ \\
\hline Bp ANN & 150 & $\begin{array}{l}\text { FRR:1.8 } \\
\text { FAR: } 2\end{array}$ \\
\hline Bayes classifiers [22] & $94 / 1247$ & $\begin{array}{l}\text { FRR: } 2.19 \\
\text { FAR: } 3.5 \\
\end{array}$ \\
\hline \multirow{3}{*}{ HMM [ 21 ] } & $2 / 120$ & $\begin{array}{l}\text { FRR:6.67 } \\
\text { FAR:0.0 }\end{array}$ \\
\hline & $40 / 1440$ & $\begin{array}{l}\text { FRR:9.94 } \\
\text { FAR:0.5 }\end{array}$ \\
\hline & $2 / 1100$ & $\begin{array}{l}\text { FRR:11.3 } \\
\text { FAR:2.0 }\end{array}$ \\
\hline String Matching [ 20] & $102 / 1232$ & $\begin{array}{l}\text { FRR:2.8 } \\
\text { FAR:1.6 }\end{array}$ \\
\hline PDF Classifiers [19] & $5 / 25$ & FAR:5 \\
\hline
\end{tabular}

\section{OUR FUTURE WORK}

As we could observe, despite the vast amount of work performed thus far for offline \& online signature verification, there are still many challenges in this research area. Signatures may be written in different languages and we need to undertake a systematic study on this. One problem of this area is, for security reasons, it is not easy to get a signature dataset of real signatures (such as banking documents) available to the signature verification system. Publicly availability of signature datasets of real documents would make it possible to define a common experimentation protocol in order to perform comparative studies in this field. Researchers have used different features for signature verification. Combination of different classifiers as well as novel classifiers should be explored in future work to enhance performance. 


\section{CONCLUSIONS}

According to our study, in the learning process \& in the training process of the system there is still room for the enhancement of the result. As the above described study shows that the algorithm which is used to analyze complex strokes of the signatures is still not satisfying. There is still further scope of improvement. Accordingly in this survey we noted that all the published work is based on foreground information. A combination of background and foreground information may be considered for better results in the future.

\section{ACKNOWLEDGEMENTS}

We express our sincere gratitude to $\mathrm{Dr}$.Mallikarjun Hangarge for supporting us in the entire manner for writing the paper.

\section{REFERENCES}

[1] K. N. Pushpalatha, Aravind Kumar Gautham, D. R.Shashikumar,K. B. ShivaKumar, and Rupam Das "Offline Signature Verification with Random and Skilled Forgery Detection Using Polar Domain Features and Multi Stage Classification-Regression Model", International Journal of Advanced Science and Technology, Vol.59, (2013), pp.27-40 .

[2] Omid Mirzaei , Hassan Irani and Hamid Reza Pourreza "Offline Signature Recognition using Modular Neural Networks with Fuzzy Response Integration", 2011 International Conference on Network and Electronics Engineering, IPCSIT vol.11 (2011) (C) (2011) IACSIT Press, Singapore.

[3] Khamael Abbas, Al-Dulaimi "Handwritten Signature Verification Technique Based on Extract Features", International Journal of Computer Applications (0975 - 8887), Volume 30- No.2, September 2011.

[4] Priya Metri, Ashwinder Kaur, "Handwritten Signature Verification using Instance Based Learning", International Journal of Computer Trends and Technology- March to April Issue 2011.

[5] Mehdi Radmehr, Seyed Mahmoud Anisheh,Mohsen Nikpour,Abbas Yaseri, "Designing an Offline Method for Signature Recognition", World Applied Sciences Journal 13 (3): 438-443, 2011,ISSN 1818-4952,(C) IDOSI Publications, 2011

[6] M Taylan Das, Canan Dulger,H. Ergin Dulger, "Offline signature Verification (SV) using the Chisquare statistics", International Journal of Biometrics, Volume 3 Issue 1, December 2011,Pages 2-12.

[7] Srikanta Pal,Michael Blumenstein,Umapada Pal,“ Automatic Off-Line Signature Verification Systems: A Review", IJCA Proceedings on International Conference and workshop on Emerging Trends in Technology (ICWET), (14):20-27, 2011.

[8] Minal Tomar and Pratibha Singh, "A Directional Feature with Energy based Offline Signature Verification Network", International Journal on Soft Computing ( IJSC ), Vol.2, No.1, February 2011.

[9] Dakshina Ranjan Kisku, Phalguni Gupta, Jamuna Kanta Sing,"Offline Signature Identification by
Fusion of Multiple Classifiers using Statistical Learning Theory", International Journal of Securityand Its Applications, Vol. 4, No. 3, July, 2010.

[10] Dr. Daramola Samuel, Prof. Ibiyemi Samuel, "Novel Feature Extraction Technique For Off-line Signature Verification System", International Journal of Engineering Science and Technology Vol. 2(7), 2010, 3137-3143.

[11] Shashi Kumar D. R, K. B. Raja, R. K. Chhotaray, Pattanaik Sabyasachi," Off-line Signature Verification Based on Fusion of Grid and Global Features Using Neural Networks", International Journal of Engineering Science \& Technology, vol.2(12), 2010, 7035-7044.

[12] Samaneh Ghandali,Mohsen Ebrahimi Moghaddam, “Off- Line Persian Signature Identification and Verification Based on Image Registration \& Fusion", Journal of Multimedia, Vol. 4,No 3, (2009), 137,144, Jun 09. doi:10.4304/jmm.4.3.137-144.

[13] Ramachandra A C, Ravi J, K B Raja,Venugopal K R And L.M Patnaik,"Signature Verification using Graph Matching and Cross-Validation Principle", International Journal of Recent Trends in Engineering, Vol 1, No. 1, May 2009.

[14] Larkins, Mayo M.,"Adaptive Feature Thresholding for off-line signature verification", Image and Vision Computing New Zealand, 2008. IVCNZ 2008, 23rd International Conference, page no:1-6. [15]. Dr.Mohammed J. Alhaddad", Multiple Classifiers to verify the Online Signature", World of Computer Science and Information Technology Journal (WCSIT), ISSN: 2221- 0741Vol. 2, No. 2, 46-50, 2012.

[15] Ahmed Galib Reza,Hyotaek Lim \& Md Jahangir Alam, "An Efficient Online Signature Verification Scheme Using Dynamic Programming Of String Matching”, ICHIT 2011,LNCS 6935,pp.590597,2011.

[16] Gruber C, Gruber T, Krinninger S, Sick B. ”Online Signature Verification With Support Vector Machines Based on LCSS Kernel Functions", Published in: Systems, Man, and Cybernetics, Part B: Cybernetics, IEEE Transactions on (Volume:40 , Issue:4 ), Biometrics Compendium, IEEE,Publication Year:2010, Page(s): $1088-1100$.

[17] Zhong-HuaQuan, De-Shuang Huang, Kun-Hong Liu, Kwok-Wing Chau,"A Hybrid HMM/ANN Based Approach for Online Signature Verification“,Published in:, Neural Networks, IJCNN 2007, page no 402-405.

[18] Kiran, G.V., Kunte, R.S.R., Samuel, S. "On-line signature verification system using probabilistic feature modeling",Published in:Signal Processing and its Applications, Sixth International, Symposium on 2001 (Volume:1 ), page no:355.

[19] A.K Jain, F.D Griess, \& S.D.Connell,"Online Signature Verification", Pattern Recognition, 35(2002)2963- 2972. 
[20] Mingfu Zou , Jianjun Tong , Changping Liu, Zhengliang Lou "On-line signature verification using local shape analysis" , Published in: Document Analysis and Recognition, 2003. Proceedings,page no:314-318,vol. 1.

[21] Alisher Kholmatov, Berrin Yanikoglu "Biometric Authentication Using Online Signatures ",In Proc. ISCIS, Springer LNCS-3280 (2004) 373- 380.

[22] Julian Fierrez Aguilar, Loris Nanni, Jaime Lopez "An OnLine Signature Verification System Based on Fusion of Local and Global Information", T. Kanade, A. Jain, and N.K. Ratha (Eds.): AVBPA 2005, LNCS 3546, pp. 523-532, 2005, Springer-Verlag Berlin Heidelberg 2005.

[23] M.Khalid, Hamam Mokayed, R.Yusof and OsamuOno,'Online Signature Verification with Neural Networks Classifier and Fuzzy Inference", Third Asia International Conference on Modelling \& Simulation, 2009, AMS09, page no:236-241. 